\title{
Modeling of Internally Recycled Material in Fibreboard Production Facility as a Tool for Economic and Environmental Assessment
}

\author{
Aleksandr Vititnev, Roman Marchenko, Anastasiya Rubinskaya, and \\ Anna Shishmareva
}

\begin{abstract}
A rationale is presented for the wood fibre process modeling of internally recycled content in fibreboard production. Experimental studies were employed to obtain mathematical dependences in order to confirm the possibility of reusing wood fibre at various stages of the technological process. A wood fibre process model of internally recycled content was accrued out in which each processing stage was presented separately. Two methods for the preparation of wood fibre for reuse in fibreboard production were considered. To assess the effectiveness of the technologies proposed, the process modeling of internally recycled content was assessed from an economic and environmental point of view.
\end{abstract}

Keywords: Wood fibre; Wood waste; Wood fibre recovery; Internal recycling; Modeling of internally recycled wood; Economic and environmental rationale

Contact information: Reshetnev Siberian State University of Science and Technology 31, Krasnoyarskii Rabochii Prospect, Krasnoyarsk 660000 Russian Federation;

*Corresponding author: sanekvititnev@yandex.ru

\section{INTRODUCTION}

The need to save on raw materials motivates the tendency towards reduction in wood quality requirements. Logging waste, low-value wood, chunk waste, and soft waste from wood-sawing and woodworking currently constitute a potential raw material basis for waste recycling.

The term recycling is legislatively defined in Russian Federal Law No.89-FZ dated 24 June 1998 Concerning Production and Consumption Waste, as follows: waste utilisation is the use of waste in the production of goods (products), performance of works, provision of services, including the reuse of waste for its planned purposes (recycling). Therefore, recycling is to be understood as the reuse of recycled waste for production and consumption purposes. According to the standardisation system, recycling is the recovery of waste, discharges, and emissions from the technogenesis process (Wan et al. 2014).

There are two possible ways to recover waste: returning it to the production cycle after proper preparation (regeneration) and extracting useful components for reuse (recuperation) (Kormishkina 2017). Many advanced countries have been recycling wood waste for more than 10 years. These countries include Finland, Sweden, Japan, and Germany (Hebert-Ouellet et al. 2017).

The recycled fibre market is developing steadily in almost all industries. Recycled fibre can serve as a low-cost alternative to new wood fibres in many products (Grossmann and Zelm 2016). In addition to cost saving, wood fibre internal recycling has several advantages. First, it prolongs the life cycle of raw materials and allows the creation of new products without any additional deforestation (Ihnat et al. 2015a,b, 2018; Irle et al. 2018). Second, it prevents the accumulation of wood waste and the formation of landfills. Third, internal recycling means fibre reuse, and if it is carried 
out efficiently (in market conditions), it provides economic and environmental benefits (Michanickl 1996; DaCunha et al. 2016; Viger-Gravel et al. 2017; Zeng et al. 2018; Ihnat et al. 2018, 2020).

Different fibreboard production stages inevitably release a large amount of wood waste: impresfiner water removals (cork water containing up to $11 \%$ wood particles). Examples include transverse-longitudinal fibreboard waste from panel sizing machines (3 to 5\%); fibre from forming machines entering wastewater (2 to $4 \%$ ); and bio-rejects (10 to $12 \%)$.

The types of fibreboard waste mentioned above account for 16 to $32 \%$ of the total production of semi-finished wood fibre products in this production. They pose a serious problem, as they are currently unused or only partially used at existing fibreboard enterprises. In fibreboard production, the utilisation of wood fibre waste is not provided for within technological processes. Sometimes, part of this waste is utilised in the basic processes (Mokhirev et al. 2015).

Due to the lack of fibre internal recycling technologies, its reuse in the production process in most cases negatively affects the quality of boards. This work presents a detailed analysis on the application of a fundamentally new and comprehensive approach to the internal recycling of secondary wood resources involving the utilisation of wood fibre recovered from wastewater and specially prepared recycled fibre from panel sizing fibreboard waste (Rubinskaya 2007; Morozov 2016).

\section{EXPERIMENTAL}

\section{Theoretical Study Methods}

Internal recycling is a type of technology that makes it possible to recycle waste internally within a technological process so that the waste is returned to the production cycle. It differs from utilization, as it uses processed raw materials for their intended purposes. For example, scrap metal is used in steel production, wastepaper in paper and cardboard production, etc. (Zemskova2017). The factors influencing practicality and economic benefit must be considered, including production cost, energy consumption, labor intensity, complexity of dismantling operations, etc. (Hubbe et al. 2007).

The wood waste internal recycling technology consists of several sequential stages (depending on the type of waste) (Fig.1). At the initial stage, wood waste is collected at all stages of source raw material processing. This is achieved by implementing such methods as recovering wood fibre from wastewater and using specially-prepared secondary fibre after panel sizing of finished boards in rotary cutting mills.

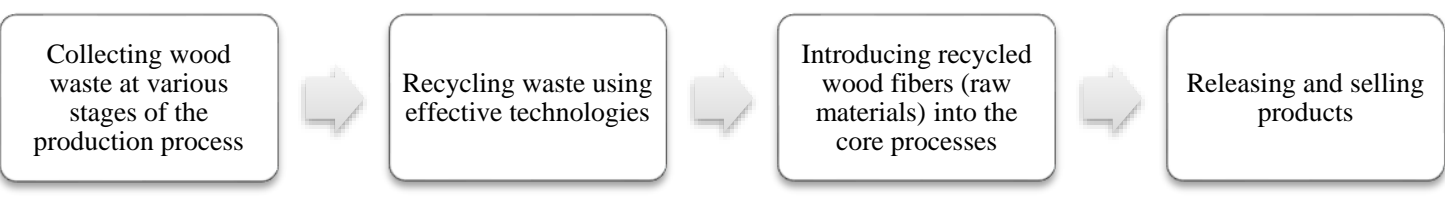

Fig. 1. Wood fibre recycling technology

This stage ensures the maximum level of wood processing. Next, secondary wood fibre is prepared. At the $3^{\text {rd }}$ internal recycling stage, wood waste is returned to the basic processes, which allows the production of additional finished products (Ihnat et al. 2015; Kosenkova et al. 2020). Thus, wood fibre internal recycling ensures the comprehensive use of existing raw materials by returning recovered wood fibre to the 
basic processes.

The materials used in this study are wood fibre recovered from industrial wastewater by the dispersive flotation method and bio-rejects in the form of chunk waste from producing composite boards.

Wood fibre waste subjected to thermal treatment at high temperature and pressure is an "inactivated" fibre that, when recycled in high-speed cutting mills, is incapable of reforming strong inter-fibre bonds in the resulting finished boards due to a process called "irreversible cornification" (Thiffault et al. 2018).

This study used laboratory equipment to assess the effectiveness of internal recycling secondary wood waste in fibreboard production. A processing unit based on the dispersive flotation method was used to recover wood fibre, and an MR-4 rotary cutting mill was used to prepare secondary fibre after panel sizing.

Figure 2 is a functional diagram of the dispersive flotator, which gives a visual representation of the flotation process stages and their mutual influence. A dry milling plant is described next. The general view and technical characteristics of the rotary cutting mill are given in Fig. 3.

Performance process

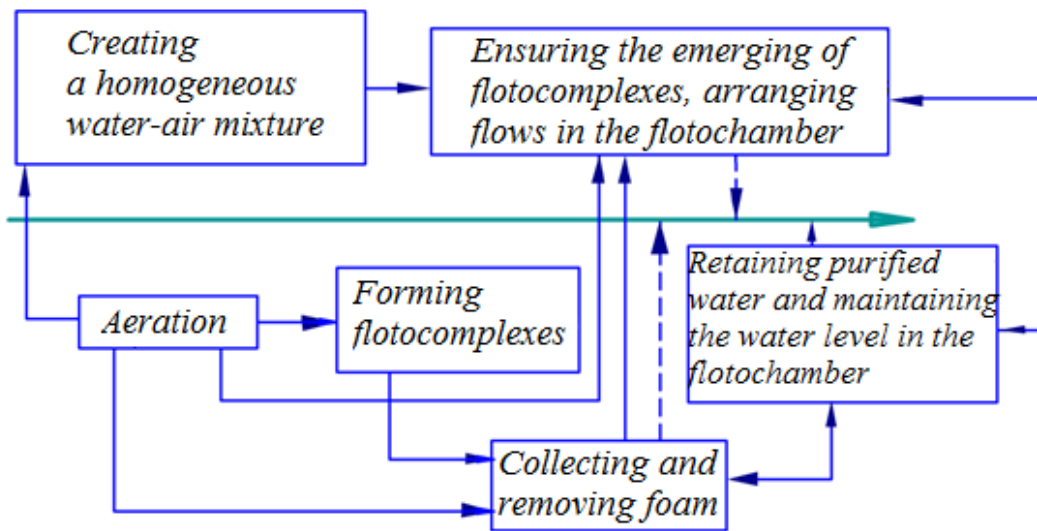

Protecting the centrifugal-type pump from internal and external destabilising factors; ensuring the stable water-air ratio in the mixture; regulating basic technological parameters;

maintaining the stable level of water surface in the flotochamber.

- functional link (influence on the process and its stages) ---- direct or indirect influence on the cleaning effect

Fig. 2. Functional diagram of the dispersive flotator

The MR-4 machine for dry grinding and preparation of wood waste consists of a housing with a shaft 4 on which rotor cutters 1 are located chequerwise. A stator cutter 3 having two bevel angles is attached to the side covers of the housing with adjusting holding devices. A separator 6 is installed inside the housing along the cylinder generatrix to defibre secondary wood after grinding. The separator regulates the grinding time (the time of keeping wood fibre in the grinding area between the rotor and the separator). The separator is a perforated metal mesh having different mesh sizes that serves as a sorting device for fibre ground into fractions. 


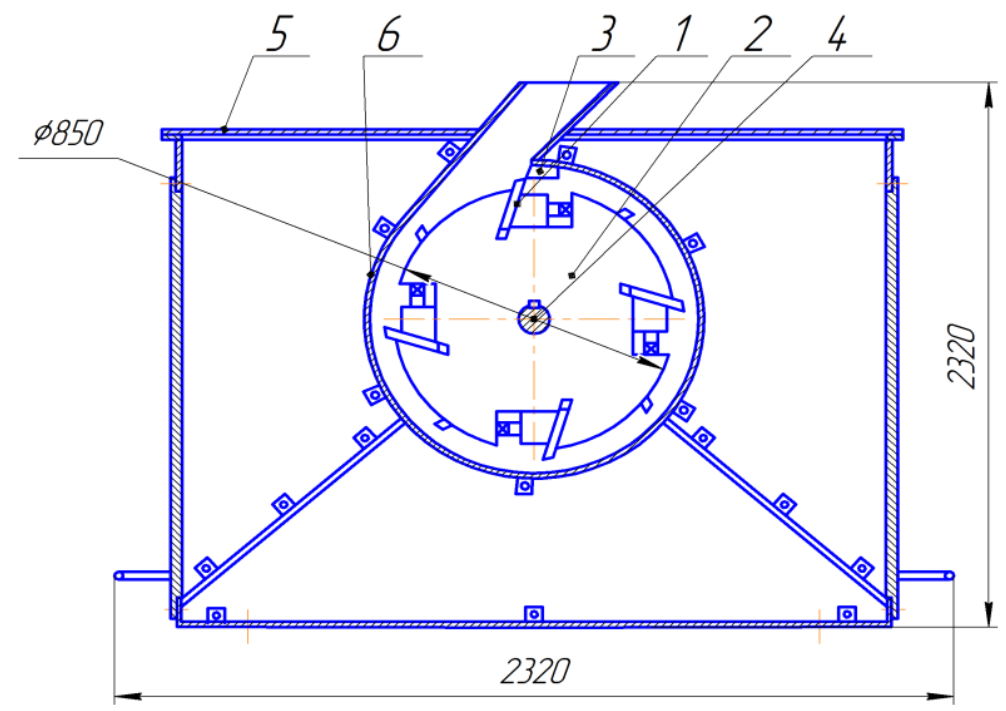

Fig. 3. General appearance of the MR-4 laboratory rotary cutting mill ( 1 - rotor cutters; 2 - pivot; 3 - stator cutter (cutting anvil); 4 - shaft; 5 - machine housing; and 6 - separator)

\section{Experimental Study Methods}

The process of cleaning wastewater from fibreboard production containing wood fibre creates fibre-containing sediments that require reutilisation in the basic processes. One of the main objectives of this work was to determine the physical and mechanical characteristics of fibreboard by varying the amount of recovered wood fibre in the basic composition.

Single-factor experiments were planned to determine the maximum possible content of secondary wood resources in the basic composition, and the main characteristics of the models were selected, making it possible to develop and obtain mathematical models of the dependence of fibreboard bending strength on the mass fraction of recycled fibre in the basic wood fibre composition. Table 1 shows the input and output parameters of these experiments.

Table 1. Experiment Input and Output Parameters

\begin{tabular}{|c|c|}
\hline Parameter & Designation \\
\hline \multicolumn{2}{|l|}{ Input parameters (controllable factors) } \\
\hline Mass fraction of fibre recovered from wastewater, per unit volume (\%) & $q$ \\
\hline Mass fraction of recycled fibre from panel sizing, per unit volume (\%) & $v$ \\
\hline \multicolumn{2}{|l|}{ Output parameters (controllable factors) } \\
\hline $\begin{array}{l}\text { Tensile strength of fibreboard under static bending, with recovered fibre } \\
\text { added (MPa) }\end{array}$ & $\sigma_{\text {irf }}$ \\
\hline $\begin{array}{l}\text { Tensile strength of fibreboard under static bending, with fibre after panel } \\
\text { sizing added (MPa) }\end{array}$ & $\sigma_{\text {ips }}$ \\
\hline
\end{tabular}

\section{Methodology for Assessing the Economic and Environmental Effectiveness of Wood Fibre Recycling}

When assessing the effectiveness of wood fibre internal recycling, attention should be paid to the economic and environmental aspects of the internal recycling process. In this study, the term wood fibre internal recycling effect includes the cumulative economic and environmental effect of the process (Table 2).

The economic aspect is an overall economic effect of the internal recycling process (savings by reducing source raw material consumption, increasing sales revenue, reducing waste disposal costs, etc.). The environmental aspect reflects the degree of preventing the impact of waste on the environment, i.e., the reduction in hazardous emissions into wastewater and the atmosphere (Moiseeva and Shishmareva 2020). 
Table 2. Criteria for the Economic and Environmental Assessment of the Effect of Recycling

\begin{tabular}{|c|c|}
\hline Indicator & Calculation method \\
\hline & Environmental effect \\
\hline \multirow{2}{*}{$\begin{array}{l}\text { Reducing } \\
\text { environmental impact }\end{array}$} & $E_{\text {env. }}=\Delta B_{\text {env }} /\left(C+E_{n} \cdot K\right)$ \\
\hline & $\begin{array}{l}\text { where } \Delta B_{\text {env }} \text { is the decrease in the value of the adverse } \\
\text { environmental impact indicator, } C \text { is the cost of measures aimed } \\
\text { at protecting the environment from negative impacts, } K \text { is capital } \\
\text { investments that determine the effect and } E_{n} \text { is the effectiveness } \\
\text { standard for bringing capital investments to annual level. }\end{array}$ \\
\hline \multicolumn{2}{|r|}{ Economic effect } \\
\hline \multirow{2}{*}{$\begin{array}{l}\text { Saving source raw } \\
\text { materials }\end{array}$} & $E=E_{2}$ \\
\hline & $\begin{array}{l}\text { where } E_{2} \text { is the volume of wood raw materials obtained in the wood } \\
\text { waste internal recycling process using various technologies. }\end{array}$ \\
\hline \multirow{3}{*}{$\begin{array}{l}\text { Additional sales } \\
\text { revenue }\end{array}$} & $P=B_{2}-C \cdot C_{2}$ \\
\hline & $B_{2}=V_{\mathrm{gp} 2} \cdot Z \cdot C \cdot C_{2}$ \\
\hline & $\begin{array}{l}\text { where } V_{\mathrm{gp} 2} \text { is the volume of products obtained from recycled wood } \\
\text { raw materials, } Z \text { is the average market selling price of the product, } \\
\text { and } C \cdot C_{2} \text { is the cost of products made from internal recycled wood } \\
\text { raw materials. }\end{array}$ \\
\hline
\end{tabular}

Maximum possible utilisation of recycled fibre is of great environmental importance in connection with the preservation of forests and the sanitary clean-up of landfills for fibreboard production waste that tend to decay and pollute underground waters, soils, and the atmosphere. The recycling effect can be assessed at various stages of the production process.

\section{RESULTS AND DISCUSSION}

\section{Theoretical Study Results}

Based on the above technologies for the utilisation and processing of recycled wood fibre, a process modeling of internal recycling was developed for wood waste in fibreboard production, providing the possibility of predicting and supplementing areas where it is possible to include secondary resources in the basic processes (Fig. 4).

The process modeling of internally recycled content combines all wood processing stages. At the initial stage, raw materials are prepared taking into account the technology being applied and the final goal, i.e., release of a specific type of product. At the next stage, basic raw materials are put into production for further processing. Stage III involves the production of a wood-fibre mat.

The red zones X1 and X2 are production stages at which it is possible to collect fibre to include it in the internal recycling process. Zone X1 is a section of the technological process in which the recovery of recycled fiber from wastewater takes place using a dispersion flotation device, which does not require additional processing of recycled fiber and goes directly to the wood pulp before the production machine for by mat from a wood-fibre. Zone X2 is a section for sizing cutting of finished fibreboard, since is "inactivated" fibre, which requires additional, special processing. The slitter cuttings must be fiberized using the shredder suggested in the article, that is, "properly prepared" before they can be added back to the process. The green zone (the recycling point $-\mathrm{R}$ ) is a process zone where it is possible to return waste fibre into the production process as raw material for additional production output. This point is the headbox before the production machine to form a mat from wood fiber. 
According to the present experimental results, this technology of reuse of secondary resources does not require additional phenol-formaldehyde resin, while maintaining the physical and mechanical characteristics of the finished board.

It is possible to assess the internal recycling efficiency using the process modeling of internally recycled content, which represents a cumulative effect of returning waste obtained at various stages of the production process to the basic processes, i.e., economising on raw materials (E), profits that can be derived from the sale of additional products $(\mathrm{P})$, and reduction of payments for environmental pollution.

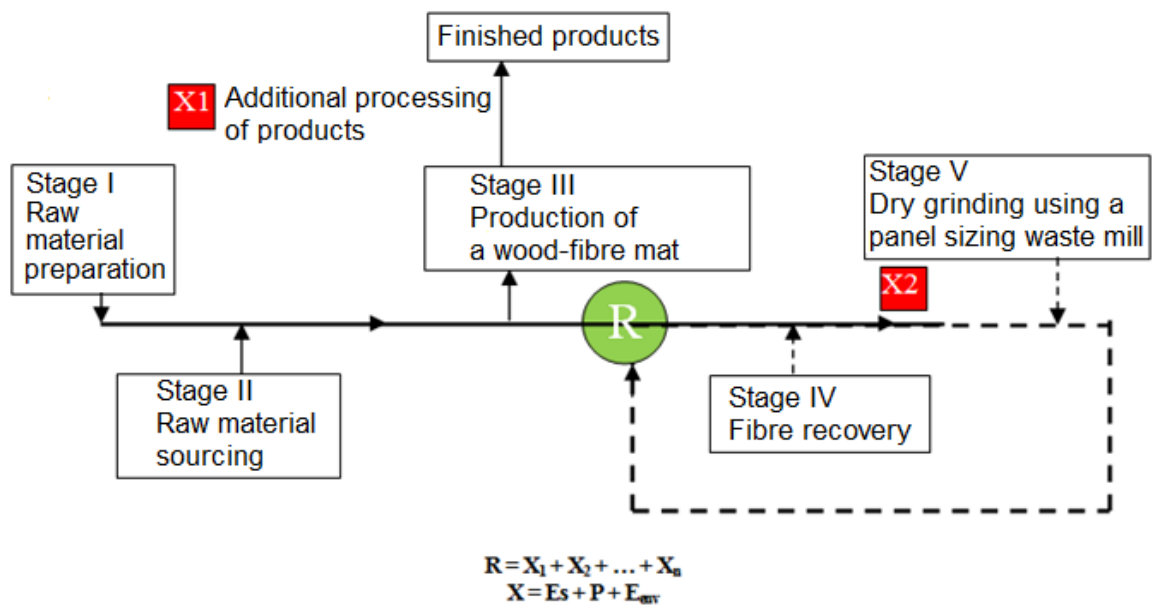

Fig. 4. Process modeling of internally recycled wood fibre in fibreboard production

\section{Experimental Study Results}

This work presents the studies on the possibility of using fibre-containing sediments in the basic wood fibre composition and waste that is generated during panel sizing of finished boards specially prepared in a rotary cutting mill. The experiments assessed the quality of recovered fibre. The recovered wood fibre retains all its properties that are inherent in the basic fibre, and it does not require any additional processing (grinding, gluing), compared with the existing wood fibre recovery methods. Therefore, wood fibre recovered using flotation equipment can be utilised as part of the basic wood fibre composition (Rubinskaya 2007). Other studies have shown that when separating the fibres of recycled particleboard content in a rotary cutting machine, the characteristics of the prepared fibre correspond to the quality characteristics of wood fibre that is used in the basic processes (Chistova 2010; Morozov 2016).

To establish the maximum possible mass fraction of fibre recovered and prepared after panel sizing in the initial wood fibre composition without a reduction in its quality and in the physical and mechanical characteristics of the final product, the tensile strength was determined under static bending in industrial conditions. Mathematical models were obtained, describing the dependence of static bending strength on the mass fraction of recovered fibre (Eq.1) and fibre after panel sizing (Eq.2) in the basic composition,

$$
\begin{aligned}
& \sigma_{\text {irf }}=35.413+0.379 q-0.07 q^{2} \\
& \sigma_{i p s}=34.725+0.623 v-0.04 v^{2}
\end{aligned}
$$

where $q$ is mass fraction of fibre recovered from wastewater, and $v$ is mass fraction of recycled fibre from panel sizing, per unit volume.

Figure 5 presents the graphical dependence built from the obtained models and showing the influence of an input factor on an output value.

The coefficients in the mathematical models in front of the factors and their 
interactions indicate the significance of varying parameters and their effect on the qualitative indicator of fibreboards. The significance of the coefficients has been assessed using a methodology based on the Student's $t$-test.

The presence of secondary fibre in the basic composition affects the strength properties of fibreboard, which is also due to the activation of the fibre contact surface necessary for chemical interaction and the formation of hydrogen bonds at the hot pressing stage. Fine fibre has a highly developed specific surface area, and it is notable for increased segmental mobility. At the fibre contact interface, lignin structures penetrate each other, followed by the formation of carbon-carbon bonds that largely fix the inter-fibre interaction.

The preservation of physical and mechanical properties of boards is explained by the fact that the effectiveness of structure formation of a wood fibre mat is influenced not only by the degree of mass grinding, but also by the fractional grinding quality indicator that determines the morphological characteristics of wood fibre. The predominance of fines in the form of fibril plasm (Group A), a group of fibres, consisting of the most flexible and thinnest fibrous elements that act as a binder, and flour (mehlstoff) (Group B) in the total mass of fines prepared by dry grinding, characterized by large values of the length-to-diameter ratio several times higher than this indicator of other fine fractions, has a large specific surface area (Laskeev 1967). These fractions ensure bonding in boards and improve their structure.

Figure 5a shows that the mass fraction of recovered fibre in wood fibre composition affected the strength characteristics of the finished board. Figure 5b shows that with the interaction of the mass fraction factor of secondary fibre from panel sizing, there were also changes in the strength characteristics of the finished wood fibre board.

Therefore, with a recovered wood fibre content of $3.5 \%$ to $7 \%$ in the basic composition, it can be predicted that the bending strength value will vary from 33 to 35 $\mathrm{MPa}$, and with a secondary fibre content of $3 \%$ to $10 \%$, the strength board indicators will correspond to values from 36 to $37 \mathrm{MPa}$.

The graphical dependence also shows that the output value indicators corresponded to GOST 4598 (2018), EN 622 (2004). Wood fibre recovered from recirculated water as a result of flotation treatment, as well as recycled fibre after panel sizing, can and should be returned to the basic processes without disrupting the process of wood pulp grinding, gluing (additional introduction of paraffin and sulfuric acid), and without changing the board pressing temperature mode.
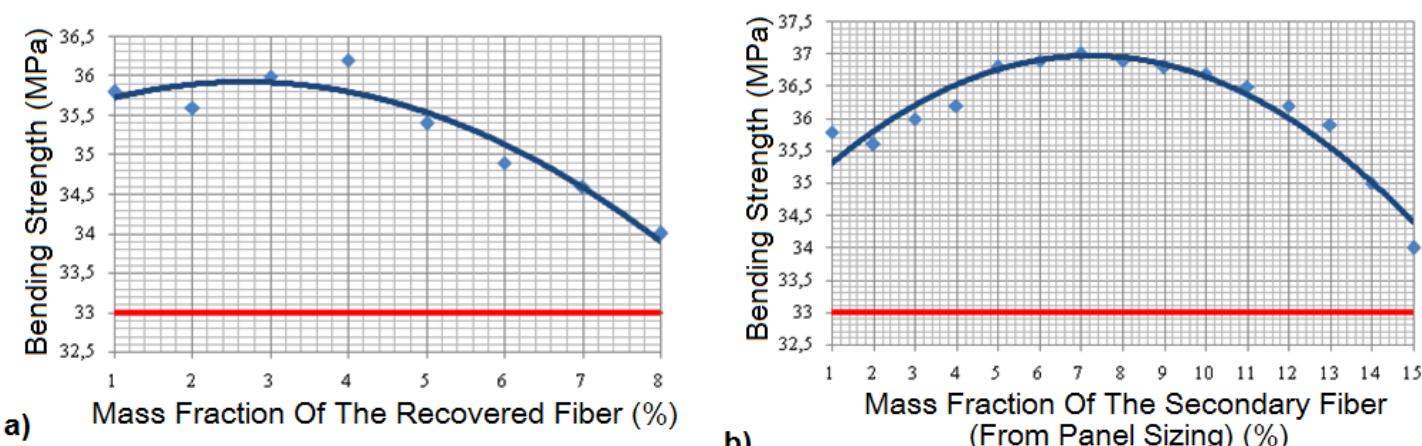

b)

(From Panel Sizing) $(\%)$

Fig. 5. Dependence of the bending strength of fibreboard on the mass fraction of the recovered fibre (a) and secondary fiber (b)

\section{Economic and Environmental Effectiveness of Wood Fibre Recycling in Fibreboard Production}

Fibreboard production is based on the technological processes of separating wood into fibres that ensure a strong interaction of the fibres with each other in the 
board formation process. Source raw materials for fibreboard production can be both round timber and technological chips obtained from low-quality wood and from hardwood and softwood waste (spruce, pine, birch, aspen, oak, beech, etc.) (Janiszewska et al. 2015; Meinlschmidt et al. 2016). The average production cost of $1 \mathrm{~m}^{3}$ of fibreboard ranges from EURO 1.1 to EURO 2.3/ $\mathrm{m}^{3}$ (as of June 2021, the EURO exchange rate is $87.41 \mathrm{RUB}$ ), depending on the quality of source raw materials, product thickness, applied technologies, etc. Fibreboard production requires a lot of materials, i.e., the share of costs for the purchase of raw materials in the total cost structure is 33 to $35 \%$. This study considered an example of wood waste internal recycling in the case of fibreboard production with a recycling volume of $94.0 \mathrm{~m}^{3}$.

Table 3. Balance of the Utilisation of Wood Raw Materials in Fibreboard Production

\begin{tabular}{|l|c|c|}
\hline \multirow{2}{*}{ Indicator } & \multicolumn{2}{c|}{ Quantity } \\
\cline { 2 - 3 } & $\mathrm{m}^{3}$ & $\%$ \\
\hline Total raw materials supplied to the workshop & 94.000 & 100 \\
\hline Product yield (finished fibreboard) & 57.216 & 60.87 \\
\hline Basic process waste, incl. & 36.784 & 39.13 \\
\hline basic process losses & 29,497 & 31.38 \\
\hline cutting a wood-fibre mat & 7.285 & 7.75 \\
\hline
\end{tabular}

With the existing fibreboard production technology, the yield of finished products was $60.9 \%$, which is a low indicator of raw material exploitation (Table 3). As specified in the fibreboard process chart (Fig. 6) and based on the process modeling of internally recycled content (Fig. 4), there were 2 red zones (waste recovery zones for returning to basic processes): the stage of cutting the wood fibre mat (losses of 7.75\%) and the stage of collecting basic process waste by recovering wood fibre (losses of $31.4 \%)$.

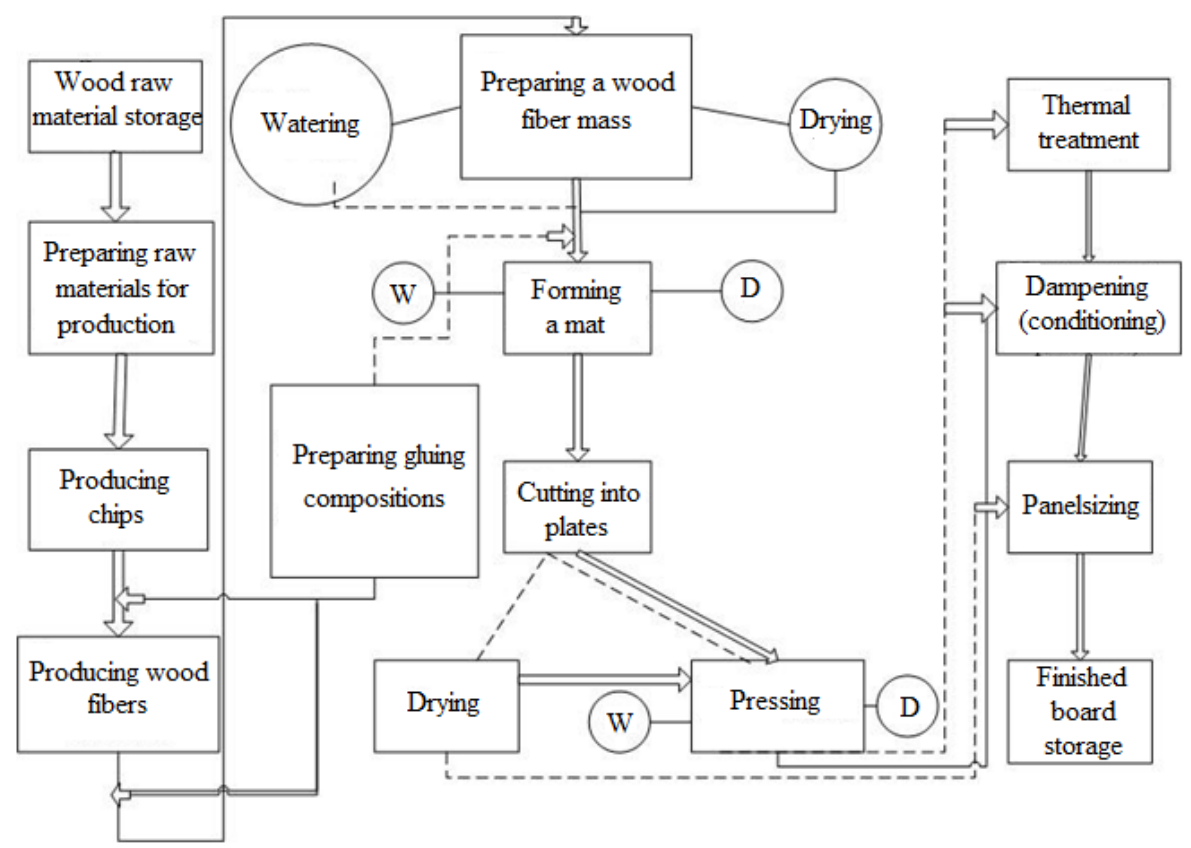

Fig. 6. Technological process of fibreboard production

At the basic process stage, when the flotator is introduced into the technological process, the quantity of waste that can be recovered and returned to the basic processes is $7 \%$, which corresponds to $2,065 \mathrm{~m}^{3}$ of wood raw material. At the wood-fibre mat 
cutting stage, the quantity of waste that can be returned to production is $94.8 \%$ which is $6,910 \mathrm{~m}^{3}$ of wood raw material.

Based on the above data regarding the production cost level of $1 \mathrm{~m}^{3}$ of fibreboard, the average production cost of fibreboard is EURO $1.69 / \mathrm{m}^{3}$; it follows that the cost of purchasing raw materials will be RUB EURO $0.59 / \mathrm{m}^{3}$. The total cost savings in the purchase of raw materials is EURO 5,300.43. The total cost of processing the entire volume of fiber, taking into account fluctuations in the level of prices and exchange rates, will amount to EURO 156.1 thousand.

Out of $8,970 \mathrm{~m}^{3}$ of the obtained raw material, the output will be $5,460 \mathrm{~m}^{3}$, which will bring an additional profit of EURO 2,210per year.

Wastewater in fibreboard production is formed during chip washing, wood fibre mass dilution, equipment, and hydraulic press cooling. The main pollutant of wastewater in fibreboard production includes suspended and soluble organic substances. Wastewater contains wood fibre, colloidal substances consisting of cellulose, hemicellulose, lignin; soluble organic substances (sugar, furfural, alcohols, aldehydes, acids, dyes, tannins); soluble and insoluble chemicals (aluminum sulfate, paraffin, etc.) used for gluing wood fibre masses. The calculation of fees for environmental pollution is regulated by Russian Federal Law No. 7-FZ dated 10 January 2002 Concerning Environmental Protection. As of 2021, the rates approved for 2018 are used with the coefficient of 1.08 [Decree No. 39 of the Government of the Russian Federation dated 24 January 2020]. The total amount of payments for economic damage caused (prior to the installation of the flotator) during fibreboard production with a volume of $57,000 \mathrm{~m}^{3}$ by all types of pollutants will amount to EURO 36.94 per year. The amount of savings for the discharge of hazardous substances will be EURO 12.93 per year.

Zone $\mathrm{X} 1$ is a section of the technological process where the recovery of recycled fiber from wastewater takes place using a dispersion flotation device. Zone X2 is a section for sizing cutting of finished fibreboard.

Table 4. Calculation of Effect the Internal Recycling

\begin{tabular}{|l|c|c|}
\hline \multicolumn{1}{|c|}{ Indicator } & $\begin{array}{c}\text { Units of } \\
\text { measurement }\end{array}$ & Value \\
\hline $\begin{array}{l}\text { Amount of wood fibre that can be returned to the basic } \\
\text { processes, including: }\end{array}$ & $\mathrm{m}^{3}$ & 8970.97 \\
\hline- Stage X1 & $\mathrm{m}^{3}$ & 2064.79 \\
\hline- Stage X2 & $\mathrm{m}^{3}$ & 6906.18 \\
\hline Cost savings on raw materials (Es), including & EURO & 5300.43 \\
\hline- Stage X1 & EURO & 1219.80 \\
\hline- Stage X2 & EURO & 4080.63 \\
\hline Sales profit obtained from returned fibre $(\mathrm{P})$ & EURO & 2212.20 \\
\hline Reduction of environmental impact fees & EURO & 12.93 \\
\hline Cumulative recycling effect, $(\mathrm{R})$ & EURO & 7525.56 \\
\hline
\end{tabular}

The internal recycling effect is a possible additional benefit from the production of products from basic process waste. Thus, the cumulative economic effect will be EURO 7,526 per year.

\section{CONCLUSIONS}

1. One way to save natural resources is to utilise plant waste as a potential raw material. In fibreboard production, wood fibre serves this purpose. To achieve this, the authors have developed a process modeling of internally recycled for secondary 
fibre that illustrates the relationship between the stages of its formation and possible utilisation. The process modeling also shows that secondary resources should be utilised in an integrated manner, for which there are technologies of recovering fibre from wastewater and processing recycled fibre during panel sizing of finished fibreboard. Also, an integrated approach to solving the internal recycling processing of secondary resources in the production of fibreboard using the technologies described above makes it possible to maintain the quality of fiberboard, which corresponds to GOST, and also makes it possible to fulfill obligations on the required quality of boards from customers.

2. Expenses allocated for this purpose can be recovered with profits, provided that the analysis and marketing studies on the further utilisation of products made from secondary raw materials are carried out in advance.

3. Another important advantage of internal recycling is the economic aspect. Greater efficiency of the production process based on the recovery of underutilized technological streams leading to a higher proportional use of raw materials in production reduces the enterprise's costs by saving on raw materials, lowers fixed production costs due to economies of scale, and leads to lower fees for environmental pollution and water basin protection.

\section{ACKNOWLEDGEMENTS}

The authors express their gratitude to the Centre for Collective Use of KSC SB RAS for supporting their research. This work was carried out under the State Assignment issued by the Ministry of Education and Science of Russia for the project: "Technology and Equipment for the Plant Biomass Chemical Processing" by the Plant Material Deep Conversion Laboratory (Subject No. FEFE-2020-0016).

\section{REFERENCES CITED}

Chistova, N. G. (2010). Recycling Wood Waste in Fiberboard Production, Ph.D. Dissertation, Siberian State Technological University, Krasnoyarsk, Russia.

DaCunha, A., Rios, P., Bourscheid, C., Kniess, D., Cordova, F., Vieira, H., and daSilveira, V.(2016). "Technological properties of particleboards made from mixture of fibres and wood shavings from Pinus spp.," Scientia Forestalis 44(112), 841-849.

Decree No.39 of the Government of the Russian Federation dated 24 January 2020 Concerning the Application of Fees for Negative Environmental Impact in 2020.

EN 622 (2004). "Fibreboards. Specifications. Part 2: Requirements for hardboards, NEQ", European Committee for Standardization, Brussels, Belgium.

GOST 4598 (2018). "Fibre boards by wet way of production. Specifications," Moscow, Russia.

Grossmann, H., and Zelm, R. (2016). Branch of Study of Wood Technology and Fibre Material Technology, Dresden University of Technology, Germany.

Hebert-Ouellet, Y., Meddeb-Mouelhi, F., Khatri, V., Cui, L., Janse, B, MacDonald, K., and Beauregard, M. (2017). "Tracking and predicting wood fibres processing with fluorescent carbohydrate binding modules," Green Chemistry 19(11), 26032611.DOI: $10.1039 / \mathrm{c} 6 \mathrm{gc03581g}$

Hubbe, M., Venditti, R., and Rojas, O. (2007). "What happens to cellulosic fibres during papermaking and recycling? A review," BioResources 2(4), 739-788. DOI: 


\subsection{6/biores.2.4.739-788}

Ihnat, V., Lubke, H., Boruvka, V., Babiak, M., and Schwartz, J. (2015a). "Straw pulp as a secondary lignocellulosic raw material and its impact on properties of insulating fiberboards. Part II. Preparation of insulated fiberboards with straw fiber content," Wood Research 60(2), 235-245.

Ihnat, V., Boruvka, V., Babiak, M., Lubke, H., and Schwartz, J. (2015b). "Straw pulp as a secondary lignocellulosic raw material and its impact on properties of insulating fiberboards, Part III. Preparation of insulating fiberboards from separately milled lignocellulosic raw materials," Wood Research 60(3), 441-450.

Ihnat, V., Lubke, H., Russ, A., Pazitny, A., and Boruvka, V. (2018). "Waste agglomerated wood materials as a secondary raw material for chipboards and fibreboards. Part II. Preparation and characterisation of wood fibres in terms of their reuse," Wood Research 63(3), 431-442.

Ihnat, V., Lubke, H., Balbercak, J., and Kuna, V. (2020). "Size reduction downcycling of waste wood. Review," Wood Research 65(2), 205-220. DOI:

10.37763/wr.1336-4561/65.2.205220

Irle, M., Privat, F., Couret, L., Belloncle, C., Deroubaix, G., Bonnin, E., and Cathala, B. (2018). "Advanced recycling of post-consumer solid wood and MDF," Wood Material Science \&Engineering 14(1), 19-23.DOI: 10.1080/17480272.2018.1427144

Janiszewska, D., Frąckowiak, I., and Andrzejak, C. (2015). "Some aspects of using post-consumer wood in particleboard production," in: Wood 2015: Innovations in Wood Materials and Processes, Brno, Czech Republic, pp.159-160.

Kormishkina, L. A. (2017). "Recycling as a new source of economic growth at the stage of neo-industrial modernisation of the Russian economy," Competitiveness in the Global World: Economics, Science, Technologies 7(1), 93-99.

Kosenkova, S., Ulanova, I., Vasiliev, A., Chursina, M.,and Nagaytseva, J. (2020). "Recycling: Methodology for converting production waste into product (raw material)," Journal of Resources, Conservation and Recycling 1(7). DOI: 10.15862/13ECOR120

Laskeev, P. K. (1967). Wood Pulp Production, Lesnaya Promyshlennost, Moscow, Russia.

Meinlschmidt, P., Mauruschat, D., and Briesemeister, R. (2016). "Waste wood situation in Europe and Germany," Chemie Ingenieur Technik 88(4),475-482.

Michanickl, A. (1996). "Recovery of fibers and particles from wood-based products," Proceedings No 7286: The Use of Recycled Wood and Paper in Building Applications, Forest Products Society, 115-119.

Moiseeva, E., and Shishmareva, A. (2020). "Complex processing assessment of wood waste of the Krasnoyarsk region forestry complex,"in: The European Proceedings of Social and Behavioural Sciences EpSBS, pp. 258-268.

Mokhirev, A., Bezrukikh Yu., and Medvedev, S. (2015). "Wood waste processing in wood enterprises as a factor in sustainable environmental management," In Inzhenerny Vestnik Dona2(2).

Morozov, I. (2016). Preparation and Utilisation of Wood Waste in Fibreboard Production, Ph.D. Dissertation, Siberian State Technological University, Krasnoyarsk, Russia.

Rubinskaya, A. V. (2007). Recovery of Wood Fibre from Wastewater and its Utilisationin Fibreboard Production, Ph.D. Dissertation, Siberian State Technological University, Krasnoyarsk, Russia.

Russian Federal Law No.7-FZ dated 10 January 2002 Concerning Environmental Protection. 
Thiffault, E., Barrette, J., Blanchet, P., Nguyen, Q., and Adjalle, K. (2018).

"Optimizing quality of wood pellets made of hardwood processing residues," Forests 10(7), 607. DOI:10.3390/f10070607

Viger-Gravel, J., Lan, W., Pinon, A.C., Berruyer, P., Emsley, L., Bardet, M., and Luterbacher, J. (2017). "Topology of pretreated wood fibres using dynamic nuclear polarization," Journal of Physical Chemistry 123(50), 30407-30415. DOI: 10.1021/acs.jpcc.9b09272

Wan, H., Wang, X.-M., Barry, A., and Shen, J. (2014). "Recycling wood composite panels: Characterizing recycled materials," BioResources 9(4), 7554-7565. DOI: 10.15376/biores.9.4.7554-7565

Zemskova, E. S. (2017). "Recycling as a specific socio-economic institute," Russian Journal of Resources, Conservation and Recycling4(4). DOI: 10.15862/14RRO417

Zeng, Q., Lu, Q., Zhou, Y., Chen, N., Rao, J., and Fan, M. (2018). “Circular development of recycled natural fibers from medium density fiberboard wastes," Journal of Cleaner Production 202, 456-464.DOI: 10.1016/j.jclepro.2018.08.166

Article submitted: April 26, 2021; Peer review completed: July 3, 2021; Revised version received and accepted: August 1, 2021; Published: August 4, 2021.

DOI: 10.15376/biores.16.4.6587-6598 